Journal of Extension Education

Vol. 29 No. 2, 2017

DOI:https://doi.org/10.26725/JEE.2017.2.29.5857-5863

\title{
Improving Livestock Services Delivery by Mobile Veterinary Units in Odisha
}

\section{Anupama Jena ${ }^{1}$ and Mahesh Chander ${ }^{2}$}

\begin{abstract}
Mobile Veterinary Unit (MVU), an ingenious way of livestock service delivery at the farmers' doorstep is being operational under the Rastriya Krishi Vikas Yojana (RKVY) in all the 314 blocks of Odisha. The study was carried out in Kandhamal district of Odisha to find out the suggestions from both the stakeholders, farmers who had availed the services of MVU and service providers (Veterinary Surgeon (VS) and Livestock Inspector (LI)) who had delivered the services to improve the efficacy of services of MVU. The analysis shows that most of the respondents expressed homogenous views and suggested more extension activities, adequate supply of free and good quality veterinary medicines, increasing manpower in MVUs, increasing frequency of repeated or follow up visits to villages, increasing salary of MVU professionals and making advanced diagnostic facility at field level to increase the livestock service delivery by MVUs.
\end{abstract}

Keywords : Mobile Veterinary Unit; Livestock service delivery; Veterinary Surgeon; Livestock inspector; Odisha

\section{INTRODUCTION}

Livestock is an important productive asset and source of income for about two-thirds of India's farm households (Birthal, 2008). The productive potential of animals mainly depends on quality of nutrition, genetic material and animal health system, and, on all these counts, India has a poor record (Ahuja et al., 2008). Hence, livestock service delivery is an important area for optimizing livestock production and productivity. Though there is an ongoing global policy of economic liberalization, still the government is trying hard to hold its feet on livestock service delivery which continues to play a central role in livestock production. India has one of the largest animal healthcare infrastructure and technical expertise in the world. It has built a vast network of over 50,000 veterinary dispensaries and centers, which together employ over $1,00,000$ veterinarians and para-veterinary staff (Pratap et al., 2012). With the changing global economic scenario, public services

1. Ph.D., Scholar and 2. Principal Scientist and Head, Division of Extension Education, ICAR-Indian Veterinary Research Institute, Izatnagar, Uttar Pradesh-243122 
are coming under pressure all over the world for not performing adequately (Sen and Chander, 2003). In order to support its large number of livestock farmers, the Department of Animal Husbandry must strive hard towards moving all livestock services to farmers' doorstep by moving away from stationary veterinary institutions and partnering with other veterinary agencies, NGOs, cooperatives, private entrepreneurs in extending the outreach of services to the farmers (Ahuja et al., 2008). To this end, it would be pertinent to have a look on unique and innovative approaches to livestock service delivery for extending it to rural poor. Few of the examples are, African countries joint delivery of public health and veterinary services (Schelling et al., 2005), Community Based Animal Health Workers (CBAHW) in countries like Africa, Afghanistan, and Kenya (Mugunieri 2004). In India, trained personnel for the same are called as paravets, Gopalmitras, link workers, Sanghamitras etc. Besides this, a number of government initiatives to deliver services at farmers doorstep, such as, Cattle Breed Improvement Programme (CBIP) under Gram Vikas Yojana (GVY) through JK trust and similar approach in the name of Mobile Veterinary Dispensary, mobile veterinary clinic, ambulatory clinic etc. in many states like Karnataka, Tamil Nadu, Andhra Pradesh, Odisha, Arunachal Pradesh, Meghalaya, Rajasthan, Gujarat, Madhya Pradesh and Chhattisgarh.
Considering this, the study was carried out to focus on livestock service delivered at doorstep through Mobile Veterinary Unit (MVU), an initiative of Odisha government funded under Rastriya Krishi Vikas Yojana (RKVY). Mobile Veterinary Units (MVU) have been initiated in all the 314 blocks of Odisha since 10th July 2010 with an objective of delivery of service at farmers' doorstep in remotest locations of the districts, according to the preferred time of the farmers, so as to enable livestock owners and consider Animal Husbandry (A.H) activities as potential livelihood option and maximize profit through livestock rearing. A team comprising one Veterinary Surgeon (VS), one Livestock Inspector (LI) and one attendant with a vehicle called MVU van reach out to organize animal health camps at distant and inaccessible villages where stationary veterinarian could not able to deliver services. Total working days for MVU in a month are 20 days. In every working day, the team organizes one camp, which caters to the livestock owners of a minimum of two villages. The camps are organized on normal working days i.e. Monday to Friday. The remaining two days are meant for compiling monthly report and attending meetings.

The study was carried out with an objective of finding out the suggestions from both the farmers and MVU team as they are directly being involved in consuming and providing livestock service. 


\section{METHODOLOGY}

The study area, Kandhamal district in Odisha state of India was purposively selected considering its geographical location i.e., high altitude, inaccessible or less accessible geographical terrains and poor communication facilities. Inadequate transportation facility and remotely located veterinary institutions made it an appropriate area for veterinary intervention through mobile veterinary services. In the 12 administrative blocks of Kandhamal district, 12 MVUs were in operation.

Three blocks were selected randomly for this study. From each block, 3 villages receiving MVU's services to a total of 9 villages were selected purposively. From these villages, 10 farmers from each village, who had availed the services of MVU, were selected. Thus, 90 farmers in total were selected for the study. Again from 12 MVUs of Kandhamal district, 12 veterinarians and 11 livestock inspectors, who were working in MVUs, were selected to study the perspectives of service providers.

\section{Data Collection}

Primary data were collected from the farmers and the service providers through a pre-tested interview schedule. A pretested questionnaire was distributed to all the veterinarians and livestock inspectors during the monthly meeting to get their response on functioning of MVUs.
Both the respondents, farmers and service providers (VSs and LIs) were requested to give their 5 most important suggestions to improve the livestock service delivery of MVU in an order from most important to least important. From both categories of respondents, seven most important suggestions came up separately.

\section{Analytical Framework}

The collected primary data were subjected to weighted mean score analysis. Total Weighted Score (TWS) was calculated by adding each respondent's score. Using the following formula, Total Weighted Mean Square (TWMS) was calculated.

Where,

$$
\begin{aligned}
& \text { TWMS }=\text { TWS } / \mathrm{N} \\
& \text { TWS= Total Weighted Score } \\
& \text { N= No of respondents } \\
& \text { Based upon the values of }
\end{aligned}
$$
TWMS, the stakeholders' suggestions to improve the efficacy of service delivery by MVU were ranked.

\section{FINDINGS AND DISCUSSION}

\section{Suggestions of Farmers to improve Efficacy of Livestock Service Delivery by MVU}

Data in Table 1 reveal that adequate supply of free veterinary medicine was prioritized as most imp suggestion for improving efficacy of livestock service delivery by MVU, felt by maximum livestock farmers of Kandhamal district 
of Odisha followed by more number of training programmes with TWMS of 4.62 and 4.33 respectively. It could further be inferred that frequent visit to same village covering the width and breadth of the jurisdiction, well-equip diagnostic facility in field, strengthening human resources in MVU, following up the cases and service delivery limited to early morning were the suggestions revealed by farmers in the order of priority with respective TWMS values of $2.92,1.05,0.88,0.83$ and 0.58 , respectively.

Table 1.

Ranking of Farmers' Suggestions to improve Livestock Service Delivery by MVU

$(n=90)$

\begin{tabular}{|c|l|c|c|c|}
\hline $\begin{array}{c}\text { S1. } \\
\text { No }\end{array}$ & \multicolumn{1}{|c|}{ Constraints } & TWS & TWMS & Rank \\
\hline 1. & $\begin{array}{l}\text { Adequate supply of free } \\
\text { veterinary medicine }\end{array}$ & 416 & 4.62 & I \\
\hline 2. & $\begin{array}{l}\text { More number of training } \\
\text { programmes }\end{array}$ & 390 & 4.33 & II \\
\hline 3. & Frequent visit to same village & 263 & 2.92 & III \\
\hline 4. & $\begin{array}{l}\text { Well-equipped diagnostic } \\
\text { facility in field }\end{array}$ & 95 & IV \\
\hline 5. & $\begin{array}{l}\text { Strengthening human } \\
\text { resources in MVU }\end{array}$ & 80 & 0.88 & V \\
\hline 6. & Follow-up of cases & 75 & 0.83 & VI \\
\hline 7. & $\begin{array}{l}\text { Service delivery limited to early } \\
\text { morning }\end{array}$ & 53 & 0.58 & VII \\
\hline
\end{tabular}

\section{Suggestions of Service Providers to improve Efficacy of Livestock Service Delivery by MVU}

Data in Table 2 envisage that conducting 'extension activities' such as awareness camps, training programmes was the most important suggestions expressed perceived by both the service providers i.e. VSs and LIs to improve livestock service delivery of MVUs.
Increased remuneration to staff was the second most important suggestion by LIs with TWMS of 4.09 while the same was the 4th most important suggestion by most of the VSs. Adequate medicine distribution and increased 'staff strength' to deliver the veterinary services properly was the second and third most felt suggestion by the service providers, respectively. Achievable target in terms of number of villages to be covered, number of cases 
to be treated, number of vaccination to be done in a month etc. should be well designed by taking all the factors into consideration was the 4th and 6th most important suggestions by LIs and VSs, respectively.

Table 2.

\section{Ranking of Service Providers' suggestions to improve Livestock Service Delivery by MVUs}

\begin{tabular}{|c|c|c|c|c|c|c|c|}
\hline $\begin{array}{l}\text { S1. } \\
\text { No }\end{array}$ & \multirow{2}{*}{ Suggestions } & \multicolumn{2}{|c|}{$\begin{array}{c}L I \\
(n=11)\end{array}$} & \multirow[b]{2}{*}{ Rank } & \multicolumn{2}{|c|}{$\begin{array}{c}\text { VS } \\
(n=12)\end{array}$} & \multirow[b]{2}{*}{ Rank } \\
\hline 1. & & TwS & TWMS & & TwS & TWMS & \\
\hline 2. & $\begin{array}{l}\text { Quality medicine in } \\
\text { adequate quantity }\end{array}$ & 34 & 3.09 & II & 38 & 3.166 & II \\
\hline 3. & $\begin{array}{l}\text { Staff strengthening in } \\
\text { MVU }\end{array}$ & 18 & 1.636 & III & 35 & 2.916 & III \\
\hline 4. & Hike in remuneration & 45 & 4.09 & I & 24 & 2 & IV \\
\hline 5. & More extension activity & 45 & 4.09 & I & 58 & 4.833 & I \\
\hline 6. & $\begin{array}{l}\text { Determining } \\
\text { achievable target }\end{array}$ & 16 & 1.454 & IV & 3 & 0.25 & VI \\
\hline 7. & $\begin{array}{l}\text { Facilities to follow-up } \\
\text { cases }\end{array}$ & 4 & 0.363 & $\mathrm{~V}$ & 17 & 1.416 & $\mathrm{~V}$ \\
\hline 8. & $\begin{array}{l}\text { Frequent visit to same } \\
\text { village }\end{array}$ & 3 & 0.272 & VI & 1 & 0.083 & VII \\
\hline
\end{tabular}

While looking into the suggestions given by both the service providers and farmers for improving efficacy of livestock service delivery by MVU gave an outlook that most of the stake holders were having homogenous type of suggestions which are discussed as follows. Suitable extension strategies should be formulated to make people aware about the importance of livestock services. Further, effective media mix for dissemination of livestock related information can enhance animal husbandry practices of the rural poor. In this aspect SDAH(State Department of Animal Husbandry) has to relook its policy to improve livestock extension services, since extension is one of the vital responsibilities of Department of Agriculture Cooperation and Farmers' welfare. Hefferman (2002) reported in his study that the most desirable feature in Odisha was, 'access to advisory service' which was an interesting finding unlike in other states, where 'credit facility' 
was deemed more desirable. Improved veterinary care using quality medicines, balanced cattle feed and quality fodder seedsinadequatequantitymaybeprovided to poor farmers through MVUs for service delivery. Service providers, viz., VSs and LIs perceived that the remuneration paid for their services was satisfactory. Providing adequate remuneration will motivate them to perform better in their jurisdiction, despite the distance and difficult accessibility of villages. Shortage of staff in MVU, Kandhamal district was the major hindrance in service delivery by MVU, leading to overburdened work to block veterinary officers and additional block veterinary officers, who had simultaneously to work at Veterinary dispensary and MVU and thereby the service delivery become less effective noticeably.

Policy decisions should be made to introduce more than one MVU in each block considering livestock population and farmers' need. Appointing adequate number of VSs and LIs in each MVU will make the service providers to perform well so that they can easily achieve their target delivery of quality services would be possible and follow-up of major cases with more focus on diagnostic and breeding aspects. Exclusive staff in MVUs may be appointed to carry out animal health and livestock development activities. The animal health activities should include prevention, control, diagnosis and curative services, whereas, veterinarians involved in livestock development activities should focus in extension and other activities in order to disseminate the needy technologies adopting suitable transfer of technology (TOT) strategies. According to service providers on an average, 77 villages were under coverage of each MVU, while they can only serve 40 villages maximum in a month. It delays the frequent visit of a particular village. According to prescribed guidelines, each MVU should treat 1000 cases in a month, with an average of 50 cases per day, within the short service delivery period from 7 a.m. to 11 a.m. besides vaccination, deworming and awareness camps for two villages every day. Hence, targets may be reduced for effective service delivery.

Diagnostic services by MVU should be given emphasis by establishing regional laboratories, covering a cluster of villages, for early diagnosis of diseases and proper treatment. Diagnostic tools that are fast, simple and cost effective (especially penside tests) should be developed and disseminated. It will reduce the cost and time required to dispatch samples to the central diagnostic laboratory. It will also enable farmers and veterinarians make the right/timely decisions early enough since sometimes farmers never know the results that come from the tests done in Entebbe and belated results mostly fails to save the animals. In such situation, empirical treatment incurs more expense and questions the cure. (Nakayima et al. 2016) 
Improving Livestock Services Delivery by Mobile Veterinary Units in Odisha

\section{CONCLUSION}

More focus towards extension activities with more number of training programmes, campaign, goshthi etc. will attract the farmers towards the services of MVU and will make them aware enough. Again, adequate supply of free and good quality veterinary medicines is a major factor by which more number of farmers will avail the services of MVU. Increasing manpower in MVUs, increasing salary of MVU professionals, increasing frequency of repeated or follow up visits to villages and making advanced diagnostic facility at field level would increase the livestock service delivery by MVUs. All these suggestions will help the policy makers to tune the policies accordingly, to improve livestock service delivery by MVUs.

\section{REFERENCES}

Ahuja, V., Kurup, M. P. G., Bhasin, N. R \& Joseph, A. K. (2008). Assessment and reflection on livestock service delivery system in Andhra Pradesh, In: Proc. Workshops and consultations, Mahbubnagar, Chittoor, Nalgonda and Rampachodavaram. Available at www.intercooperation.org.

Birthal, P. S., Negi, D. S., Jha, A. K \& Singh, D. (2014). Income Sources of Farm Households in India: Determinants, Distributional Consequences and Policy Implications, Agricultural Economics Research Review, 27 (1), 37-48.

Heffernan, C. (2002). The delivery of veterinary services to the poor: Findings from Orissa. In: Livestock Services and Poor. Proceedings and Presentations of the International Workshop, Bhubaneswar, India.

Mugunieri, G. L., Irungu, $\mathrm{P} \&$ Omiti, J. M. (2004). Performance of community based animal health workers in the delivery of livestock health services, Tropical Animal Health and Production, 36(6), 523-535.

Nakayima, J., Nerima, B., Sebikali, C \& Magona, J. W. (2016). An assessment of veterinary diagnostic services needs in Uganda, Journal of Veterinary Medicine and Animal Health, 8(7), 5055.

Pratap, S., Bardhan, D \& Dabas, Y. P. S. (2012). Can privatization improve animal health care delivery system? An Ex-ante analysis of dairy farmers in Tarai region of Uttarakhand, Agricultural Economics Research Review, 25, 507-514.

Schelling, E., Wyss, K., Bechir, M., Moto, D. D \& Zinsstag, J. (2005). Synergy between public health and veterinary services to deliver human and animal health interventions in rural low income settings, British Medical Journal, 331 (7527), 1264-1267.

Sen, A., \& Chander, M. (2003). Privatization of veterinary services in developing countries: A review, Tropical Animal Health and Production, 35, 223-236. 